Paideusis

\title{
Recent Scholarship on Dewey: From Screech to Scholarship
}

Douglas Jackson Simpson

Volume 16, Number 3, 2007

URI: https://id.erudit.org/iderudit/1072493ar

DOI: https://doi.org/10.7202/1072493ar

See table of contents

Publisher(s)

Canadian Philosophy of Education Society

\section{ISSN}

0838-4517 (print)

1916-0348 (digital)

Explore this journal

Cite this review

Simpson, D. (2007). Review of [Recent Scholarship on Dewey: From Screech to Scholarship]. Paideusis, 16(3), 93-98. https://doi.org/10.7202/1072493ar viewed online.

https://apropos.erudit.org/en/users/policy-on-use/ 
Review

\title{
Recent Scholarship on Dewey: From Screech to Scholarship
}

\author{
DOUGLAS J. SIMPSON \\ Texas Tech University, USA
}

When I simultaneously started reading John Dewey and the Decline of American Education: How the Patron Saint of Schools Has Corrupted Teaching and Learning (Wilmington, Del: ISI Book, 2006) by Henry T. Edmondson III and Inquiry and Education: John Dewey and the Quest for Democracy (Albany: SUNY Press, 2006) by James Scott Johnston, I had a feeling that may be compared to moving into and out of two alternate forms of reality. Sadly, my initial impressions changed very little after I concluded my readings. I say "sadly" because I did not have the opportunity to read two new works that were written by two serious students of Dewey, regardless of whether they were detractors or admirers. Instead, I had one opportunity for screech and another for scholarship. But reading works that express dissatisfaction with the reported ideas of Dewey and dissatisfaction with some of the ideas of both his critics and sympathizers has the advantage of keeping abreast of ongoing Dewey debates. We turn now to the screech and later to the scholarship.

\section{A Screeching Approach to Dewey}

In the first case as I was reading John Dewey and the Decline of American Education, I was struck by the portrayed Dewey - at very few points did I see the historical figure that I have discovered through reading his essays, books, and poetry accurately portrayed or evenhandedly analyzed. Instead, I met a largely fictional, distorted caricature of Dewey although admittedly there were moments of accurate-if overemphasized and decontextualized-descriptions of his ideas, e.g., when criticisms of Dewey's writing style and religious beliefs are mentioned. I expected better from an author who stated that he had studied Dewey for twenty years (vii), and who acknowledged that Dewey is "rarely read" (4) and "poorly understood" (xiv, 4). Whether the author has studied Dewey for two decades or not is not an issue. But it is important to recognize that Edmondson joints a strand of detractors who have helped make Dewey even more "poorly understood." Obviously, he did not appreciably restrain—or, at least, succeed in controlling - the influence of his conservative, anti-Deweyan beliefs. Certainly, to refer to Dewey as the "Devil of Educationism" (110) reveals a lack of interest in providing a considered, scholarly analysis of Dewey's influence on American education. Being excessively critical of Dewey's ideas, however, did not keep Edmondson from acknowledging that Dewey himself was "a benevolent" and "a kind, gentle, and patient man" (1-2). Likewise, he acknowledges—although such seems inconsistent with the heading "Devil of Education" - that it is "overblown rhetoric" to refer to Dewey as "the Antichrist" (2).

(C) Copyright 2007. The author, Douglas J. Simpson, assigns to Paideusis the right of first publication and educational and nonprofit institutions a non-exclusive license to use this document for personal use and in courses of instruction provided that the article is used in full and this copyright statement is reproduced. Any other usage is probibited without the express permission of the author. 
Edmondson is occasionally disarming. For example, he is prepared for people like me who think that he has seriously misunderstood Dewey and misinterpreted his writings. In addition to mentioning that he has studied Dewey since his graduate school days, he asserts that Dewey is "not that difficult to understand if one is willing to accept the obvious-namely, that his arguments are ideologically charged and philosophically vague" (11) and that "the key to unlocking the purported difficulties of his thought" is found in understanding that Dewey places his political views over his philosophical ones (11). Having claimed to have studied Dewey for two decades and that he is not difficulty to understand, Edmondson goes on to contradict himself when he says that part of the difficulty of understanding Dewey is attributable to his writing style (10-14). Repeating a string of others' criticisms of Dewey's writing style, Edmondson declares him "careless," "redundant," "inarticulate," and "intemperate and disingenuous." No doubt these qualities—as well as lacking "the key" previously mentioned-contribute to the fact that many people misunderstand and misapply Dewey's works so often (11). Although they find few other grounds of agreement, Edmondson and Johnston (2006, 3-4) agree on Dewey's writing style. Ingeniously or disingenuous, to borrow terms that Edmondson uses several times to describe Dewey's claims, he calmly says his book "is a simple exegesis of Dewey's thought" (17). Many who read Edmondson's work may conclude otherwise and think that he should had used the term eisegesis.

In rather typical fashion for many combative conservatives, the author claims that Dewey's "devastating" (113) corruption of education (which Edmondson never distinguishes from schooling) has been done directly and indirectly through his ideas and through his followers who have taken his ideas into mainstream educational thought in P-12 schools, teacher education, and society (108-114). Indeed, "Dewey's ideas have been profoundly consequential" (110) and are seen in "dull and vague shades of gray" that lead to various types of confusion (112). So, the weaknesses of contemporary educational philosophy in the United States are "largely attributable" to Dewey's influence (xiv) even though it is admittedly impossible to determine "how much influence Dewey has had" (110). Even so, it is clear that his influence has long "superseded that of the founders" of the United States (2) and has influenced "educational bureaucrats, activists, and accrediting agencies" in noticeably inappropriate directions (4). In Edmondson's accountability system, then, maliciously unsympathetic misinterpreters, overly zealous followers, and ideologically inebriated proponents are seldom considered responsible for anything that is correctly or incorrectly attributed to Dewey. To draw a modern parallel if we followed Edmondson's reasoning, Mohammed is almost completely responsible for everything a contemporary Shiite and Sunni or splinter group claims or practices regardless of their misappropriations of his teachings.

In his series of tirades against Dewey, Edmondson infrequently shows explicit connections between Dewey and present-day educational thought and practice. Instead, we find him employing phrases such as "Dewey-inspired" (112), "Dewey legacy" (112), "may go a long way toward explaining" (22), "an indelible mark" (30), "helped spawn" (31), "inheritance from" (42), "undisputed influence" (59), "the damage of" (76), "the followers of" (88), "investigations linked" (90), and "Dewey-inspired efforts" (99) to condemn and discredit and, ideally, "disinherit" Dewey (95). As noted previously, Edmondson finds it difficult to distinguish between the distortion of Dewey's followers and critics and excesses of some progressivists from the ideas of Dewey himself. Rather, he moves from such statements as contemporary education's revolt to "Dewey's revolt" (56) as though there is an unbroken, orthodox, and straight-line extension of Dewey's thought to nearly everything undesirable in education and society today. Since Edmondson thinks that Dewey has corrupted society as well as schools, it would be appropriate to alter his book's subtitle to read How the Patron Saint of Schools Corrupted Teaching and Learning and Society.

What exactly are Dewey's contributions to the corruption of education and society as seen by Edmondson? We may identify these corrupting influences by looking at what Dewey purported supported and opposed. First, what did Dewey supposedly oppose? His views are described as hostile to utilitarianism, tradition, religion (7), individual character development (13), and an academic canon 
(35). Plus, he is described as having little or no respect for his own intellectual heritage, e.g., Greek thinkers, Judeo-Christian ideas, enlightenment wisdom, and the American founders (17). Moreover, if Edmondson is correct, Dewey's ideas have led to a contemporary theory of education which revolts against authority: "a revolt against a canon of learning, a revolt against tradition, a revolt against religious values, a revolt against moral standards, a revolt against logic — even a revolt against grammar and spelling" (56). While it is true that Dewey sometimes revolted against many of the beliefs that were a part of his intellectual, religious, and culture milieu, it is unfortunate that Edmondson does not explain why Dewey revolted, the nuances of his revolt, and the contributions of some of his revolutionary ideas. Instead, we find polemics par excellence.

Second, Edmondson simplistically attaches a string of isms to Dewey. For example, he claimswith little or no qualification, explanation, or argumentation - that Dewey supported skepticism (14), experimentalism (14, 30), naturalism (16), scientism (29-30), constructivism (34), nihilism (35), and socialism (72). Worse, perhaps, is the fact that Dewey is said to support the creation of new beliefs: an alternative religion described as a universal faith in democracy (21), a new view of human nature that highly values human impulses (22), a new morality that removes responsibility from the individual and places it in the environment (24-25), a new approach to the acquisition of literacy skills and abilities known as whole language (98), and a new pseudo-curricular emphasis that has led to "the annihilation of subject material" (103). Dewey, furthermore, Edmondson claims, emphasizes a vocational rather than academic education which turns out to be neither truly vocational nor academic $(9,45,47)$, inspires values clarification programs (27), stimulates an interest in self-esteem (27), stresses learning by doing at the expense of transmitting information and understanding (37), desires socialization rather than education of students (40), promotes an ignorance of history (57ff), stimulates a betrayal of the founders' view of democracy (66ff), praises the importance of play (42), promotes an aimless growth (49), and supports dogmatic rather than critical thinking (7, 21). Finally, for this essay, Dewey represents a "surrealistic separation between theory and practice," because he was an abstract and impractical theoretician who was "a poor teacher" (32). Given this by and large unguarded series of accusations and misleading reading of Dewey's writings, it is unsurprising that Edmonson concludes his chapter titled "Democracy Betrayed" with the following statement:

Dewey subverts the educational intentions of Jefferson and of the entire founding generation. In light of the founders' aspirations, Dewey's schoolhouse revolution compromises the integrity of American leadership, deprecates moral and civic virtue, depreciates the importance of constitutional structures and processes, and thus undermines the well-being of the American republic. (76)

Edmondson's approach to Dewey, his ideas, and his influence will probably make it difficult for either a well-informed conservative or liberal scholar to appreciate his brief mistreatment of Dewey as the patron saint of schools in the USA. But there is at least one avenue to appreciating the volume more than I have suggested: the reader might imbibe deeply from a jug of Newfoundland screech as she or he reads the work. If asked why you are grinning, you could ambiguously respond, "It is not the screech," but "Tis the rum, me son." Or, if an air of scholarship is preferred, one might respond that Edmondson's book "sheds little new light [and repeats a lot of old misperceptions] on the complex nature of John Dewey's philosophy" (Attick, 2006, 90).

\section{A Scholarly Approach to Dewey}

In the work titled Inquiry and Education: John Dewey and the Quest for Democracy by James Scott Johnston, I entered a more familiar but still somewhat strange world. Familiar, I say, because I reencountered the Dewey I have studied in the past. Slightly strange, I add, because Johnston seems concerned neither to 
distort Dewey's ideas in an attempt to discredit him nor to co-opt his thoughts in an effort to claim that Dewey foresaw the latest developments in pedagogy, educational research, social philosophy, or aesthetics. Instead, the author pursues a meticulous, text-driven investigation—or, rather, inquiry—into several of Dewey's major themes-inquiry, science, experience, growth, education, community, and democracy-in an effort to show their interconnectedness and importance for schools and society. Although Johnston's conclusions will not always satisfy all interpreters of Dewey, he has written in such a way that future scholarship on the points he addresses will be indebted to his analyses. In addition, he was successful in explicating the interconnectedness of these seven concepts. On the other hand, there remains plenty of work for students of Dewey to try to indicate how these themes might imaginatively be implemented, applied, or operationalized in different schools and societies.

If this terse evaluation is on the whole correct, how did Johnston achieve his desired goal? Simply stated, the volume itself makes it clear that Johnston studied extensively, thought reflectively, wrote painstakingly, and edited meticulously. Or, to borrow a phrase from him, he engaged in what he encourages: "scrupulously conducted research" (189). His working tirelessly was essential because he attempted the nearly impossible, namely writing for "educators familiar with Dewey" and "philosophers, social theorists, historian, and others interested in Dewey" (viii). Consequently, he confesses-but shows no signs of contrition - that the book is "difficult" (viii) and that it presupposes an existing familiarity with Dewey. One may correctly doubt whether Johnston's claim that just reading "a good primer" on Dewey will be sufficient background for his work.

To make his work more easily accessible for all groups, Johnston did a masterful job of both introducing the project in under fifteen pages (1-13) and using a four-part repetitious but effective outline for each chapter, i.e., providing (1) a brief history of debate about the concepts addressed, (2) a concise overview of contemporary thinking on the same ideas, (3) a rereading of Dewey's actual statements regarding the themes, and (4) an integrative approach to understanding how the ideas examined fit together and elucidate prior and approaching concepts. In addition, the author observes that those who are not interested in either the past or contemporary debate can pass over these sections of each chapter without being significantly affected by the flow of the work. This observation may be correct but following such advice may lessen one's appreciation of Johnston's expert analysis of the historical and contemporary contributors to the debates that he examines.

In view of this overview of the themes of the book and framework of the chapters, we may wonder how Johnston approached Dewey's seven concepts of inquiry, science, experience, growth, education, community, and democracy? What are his goals and emphases and conclusions? One goal, if I understand him correctly, is to reopen discussions about Dewey's ideas and to indicate where past and current philosophers and educators have misunderstood Dewey's thoughts about the seven themes, their interconnectedness, and related theories, e.g., Dewey's reported inconsistent theories of knowledge and experience (scientific and positivistic and/or aesthetic and experiential), notions of democracy and society (rational and bureaucratic societies in the service of industry and/or inquiring and growing communities in the service of the public), and his beliefs about peaceful and/or military solutions to international problems ). In dealing with these and related tensions and, probably, inconsistencies in Dewey's evolving thought, Johnston may be more interested in showing that Dewey was neither guilty of certain isms (e.g., positivism, scientism, foundationalism, reductionism) nor being genuinely contradictory in his epistemology (scientific versus aesthetic understanding) than are some. Thus, he may be overly interested in finding ways "for Dewey to escape the charges" of his critics (12), accusations that are almost impossible to avoid given Dewey's seventy-year career of writing.

Happily, Johnston's arguments are studied, reflective, measured, fair-minded, and well-formed in a period when evidence and reason have been given a diminished roll even in certain academic circles. Moreover, he habitually selects strong representatives of the opponents and proponents of ideas, and he treats their views and arguments with the seriousness they deserve. His own conclusions regarding Dewey's theory of knowledge is that both a purely positivistic-scientific interpretation and a purely aestheticized-experiential interpretation of inquiry is misleading (86). Borrowing a phrase from Dewey 
(1938) found in Experience and Education where he says he wants to broadly describe traditional and progressive education "without the qualifications required for accurate statement"(17), a broad and inadequate description of Johnston's view of Dewey's theory of knowledge follows. He understands Dewey to be arguing for forms of intelligent inquiry and reflection (both logical as in historical and biological research and non-logical as in poetry and fiction) that are rigorous and imaginative as meaning is pursued and solutions to problems are discovered. So, he argues that Dewey "makes room for many variants of one knowing, if knowing is to be coeval with thinking" (52). This understanding is, as expected, related to Johnston's interpretation of Dewey's notion of inquiry as self-correcting thinking (113) that occurs in a democratic community where educative experience leads to growth. Inquiry in turn is "embedded in an experience" (75) that has a particular context (8-9). This contextbound inquiry is "robust" and "every bit as involved in the ordering of the data of experience as a scientific theory would promise" (103). On the point, Johnston might have developed and clarified the idea that inquiry is involved in experience. In doing so, it could help address the often polarized if not dichotomized debate surrounding Dewey's emphasis on a scientific or aesthetic approach to inquiry and experience. That is to say, if inquiry is embedded in experience, it is also embedded in aesthetic experience. The fact that experience is aesthetic does not mean that inquiry is absent, unimportant, or irrelevant. Inquiry as embedded in aesthetic experience partially allows and enables experience to be a time of making, perceiving, understanding, and meaning making.

Where is Johnston ultimately attempting to lead us with his explanations of inquiry, growth, experience, democracy, community, so forth? He has actually been telling us a little at a time throughout his work about a major interest: the importance of the school in his view of a Deweyan educative world. For instance, he says very early that his interpretation of Dewey's key themes have implications for "what Dewey considered the most important institution for the development of growth, of community, and of democracy: school" (12). Later he notes that growth's "chief means" is "(formal) education" (103). Indeed, growth needs "a formal means to facilitate the building up of a fund of meanings such that increasingly satisfying experiences can be had" (103). Additionally, he adds, "Formal education-that is, schooling - not only should facilitate the development of the habits of inquiry but also provide the conditions of this facilitation through the bringing together of children having varied experiences, with the goal of having these experiences shared" (112). "Education, that is, formal schooling, is the chief vehicle of supply for this demand ["that the public be properly educated"]" (130).

Manifestly, Johnston thinks highly of the potential role schools may play in the inquiryexperience-growth-education-community-democracy spectrum. But, like Dewey, he believes there are many other "settings where a more or less captive and impressionable audience of children is present," e.g., "at the day-care center, in family gatherings, on the television, at the movies, in the doctor's offices, on vacations" (189).

Although recognizing political and parental realities, he correctly claims, "Schooling, if done well, has the advantage of providing opportunities for learning that cannot, whether from institutional inability or parental choice, be gotten elsewhere" (189). But, he states, the public has not been able to set into motion a societal ethos and reflective habits that promote this educative spectrum in an ongoing and rich fashion (190). Paradoxically, maybe, he has already let it be known that education is "the chief vehicle for the transformation of the public, and, with the chief task of education being growth, the development of inquiry in this endeavor is central. This can occur only one child, one school, and one community at a time" (139).

These observations lead to a final question: How might we do a better-a credible-job in the future if we wish to pursue a Deweyan vision of school and society? Johnston's answer includes a variety of suggestions related to personnel, facilities, and practices that are sometimes missing to varying degrees in different classrooms and schools today. He mentions, for instances, the need for voluntarily developed schools where personal interactions, educational environments, diverse students, formalized processes, inquiring students, democratic cultures exist (193-197). He stresses that schools 
must be more professionally "self-regulating" (194) and have more educational "self-governance" (196) and that legislation should promote rather than inhibit the development of schools where inquiry, growth, community, and democracy are valued, pursued, experienced, and enjoyed. In this way, schools can be in "the service of the problems of men [and women]" and "reach out beyond themselves to the larger communities and society of which they are a part" (197).

Some may complain that Johnston appears to overestimate the strength of an inquiry-oriented school in society, ignoring Dewey's (1916) own assertion in Democracy and Education that the school is only "one means, and compared with other agencies, a relatively superficial means" when it comes to influence (4). But Johnston is aware of Dewey's belief (166) and seems interested in nurturing schools that can be as Deweyan and influential as possible in a democratic society. Weak and pseudo-Deweyan schools simply will not work. Thus, he appears satisfied to acknowledge that the school is only one educative means but dissatisfied with allowing this unique means to carelessly drift when it could supply "the means for the future citizen to think" (194) and reach out to and work with other social agencies in a broad educative mission (197). Similarly, he rightly is not happy with the conclusion that Dewey's qualification of the strength of schools means that they are not unique and crucial in what they contribute to developing educated people. Others may argue that Johnston overlooks the weaknesses of Dewey's concept of democracy and his interest in supporting the corporate and business mind. This criticism too seems misplaced, for he acknowledges that Dewey's idea of democracy needs some assistance but contests the accusation that Dewey promoted an education that is designed to promote the wishes of a capitalistic state (174-185).

Finally, it may be argued by still others that Inquiry and Education gives insufficient attention to Dewey's social philosophy and the informal and formal educative functions of other institutions and agencies. Perhaps this point is partially correct but, considering the fact that the focus of the work with regard to education is largely on schools, it is an overreaching criticism. If Johnston focuses on schools, one may question why more attention is not given to teachers and their preparation and the roles they play in the inquiry-experience-growth-education-community-democracy continuum. This query raises an important point, but given the fact that the volume as a whole focuses on the conflicting ideas of Dewey critics and sympathizers regarding the aforementioned themes, it is a minor matter regarding a major work that contributes significantly to Deweyan research. The work-unlike John Dewey and the Decline of American Education: How the Patron Saint of Schools Has Corrupted Teaching and Learning-merits the attention not only of Dewey scholars but of educators who are interested in the nature and goals of inquiry, growth, community, democracy, and education. Johnston's contribution to Deweyan research and, ideally, to educational practice is noteworthy. On the other hand, it does not merit the attention of those who are having their imaginations and emotions stimulated by a second or third round of Newfoundland screech.

\section{References}

Attick, D. (2006). Book review: John Dewey and the Decline of American Education. Education and Culture. (22) 2, 87-91.

Dewey, J. (1916). Democracy and education: An introduction to the philosophy of education. New York: The Free Press.

Dewey, J. (1938). Experience and education. New York: Macmillan Publishing Company.

Edmondston, III, H. (2006). John Dewey \& the decline of American education: How the patron saint of schools has corrupted teaching and learning. Wilmington, DE: ISI Books.

Johnston, J. (2006). Inquiry and education: John Dewey and the quest for democracy. Albany, NY: State University of New York Press. 